\title{
PEMANFAATAN REJEK HIDROPULPER UNTUK MENINGKATKAN NILAI KERTAS BEKAS SEBAGAI BAHAN BAKU INDUSTRI KERTAS
}

\author{
Taufan Hidayat ${ }^{1}$, Yusup Setiawan \\ Balai Besar Pulp dan Kertas, Jl. Raya Dayeuhkolot No. 132 Bandung \\ ${ }^{1}$ taufanhidayat@gmail.com
}

Diterima : 11 Maret 2015, Revisi akhir : 30 Oktober 2015, Disetujui terbit : 30 November 2015

\section{THE UTILIZATION OF HYDRAPULPER REJECT FOR INCREASING RECOVERED PAPER VALUE AS RAW MATERIALS FOR PAPER INDUSTRY}

\begin{abstract}
Limited case study of biorefinery implementation in paper industry has been done through the investigation of fibers component separation from hydropulper reject for papermaking. Pulper rejects was cleaned from metal contaminant, crushing, screening sequentially through the screen 6, 2, and 1 size, and drying. Reject fibers $(R)$ then mixed with Old Corrugated Container or OCC $(O)$ in the ratio of R:O as 100:0; 75:25; 50:50; 25:75; and 0:100. The handsheets then made at the basis weight of 70, 125, and $150 \mathrm{~g} / \mathrm{m}^{2}$ or GSM, followed by testing and evaluating. The results showed that the furnish of reject and OCC mixing is feasible for papermaking, and still have some opportunities to develope further mechanically, chemically, and or fiber reinforcement. Based on the evaluation of handsheets quality, it is recommended that improved 70 GSM paper suitable for wrapping paper, while improved 125 and 150 GSM papers supposed to be a lainer board and fluting medium.
\end{abstract}

Keywords: biorefinery, hydrapulper reject, wrapping paper, lainer board, fluting medium

\begin{abstract}
ABSTRAK
Studi kasus terbatas tentang penerapan biorefinery di industri kertas telah dilakukan melalui penelitian pemisahan komponen serat dari rejek hidropulper untuk dimanfaatkan kembali menjadi kertas. Rejek hidropulper dibersihkan dari pengotor logam, dicacah, disaring secara berurutan melalui saringan berukuran 6, 2, dan $1 \mathrm{~mm}$, dan dikeringkan. Serat rejek (R) dicampur dengan Old Corrugated Container atau OCC (O) dan komposisi R:O adalah 100:0; 75:25; 50:50;25:75; 0:100, kemudian selanjutnya dibuat lembaran kertas dengan gramatur 70,125 , dan $150 \mathrm{~g} / \mathrm{m}^{2}$ atau GSM. Kertas dikondisikan dalam ruang standar sebelum diuji mutu lembarannya. Hasil penelitian menunjukkan bahwa furnish campuran serat rejek dan OCC layak untuk dibuat lembaran kertas, tetapi masih memerlukan perlakuan lanjutan untuk meningkatkan mutunya. Berdasarkan peluang peningkatan mutu tersebut disarankan kertas gramatur 70 GSM digunakan untuk kertas bungkus, sedangkan kertas gramatur 125 dan 150 GSM untuk kertas lainer dan medium.
\end{abstract}

Kata Kunci : biorefinery, rejek hidropulper, OCC, kertas bungkus, kertas lainer, kertas medium

\section{PENDAHULUAN}

Secara global bahan baku industri kertas terdiri dari 55\% kertas bekas, 33\% pulp kimia kayu, 7\% pulp mekanis kayu, 3\% pulp non-kayu, dan 2\% pulp semikimia kayu. Di Indonesia bahan baku industri kertas terdiri dari 58\% kertas bekas, 35\% pulp kimia kayu, 3\% pulp semikimia kayu, 2\% pulp mekanis kayu, dan 1\% pulp non-kayu (http:// faostat3.fao.org/browse/F/FO/E). Data tersebut menunjukkan bahwa secara global maupun nasional, kertas bekas memegang peranan penting sebagai bahan baku industri kertas. Data penggunaan kertas bekas terus meningkat dari tahun ke tahun, sehubungan dengan adanya kecenderungan peningkatan industri berbasis 
biomassa (biorefinery) termasuk bioenergi yang menggunakan kayu sebagai bahan baku. Di Eropa peningkatan ini sekurang-kurangnya terpacu oleh adanya insentif, peningkatan kesadaran, dan keberterimaan yang luas dari masyarakat terhadap penerapan konsep daur-ulang (Miranda dkk., 2010), disertai dengan adanya target dan regulasi penggunaan bioenergi. Berbagai faktor lain sebagai pendorong peningkatan penggunaan kertas bekas juga telah dikaji meliputi aspek ekonomi, sosial budaya, lingkungan, dan tingkat perkembangan teknologi (Doshi, 2010).

Penggunaan kertas bekas sebagai bahan baku industri, merupakan salah satu wujud penerapan konsep daur-ulang, walaupun sebenarnya tidak semua bahan dapat didaur-ulang. Tingkat kemampuan daur-ulang bahan berbeda-beda tergantung pada jenis bahan tersebut. Kemasan kertas dan karton adalah bahan yang paling tinggi laju daur-ulangnya yaitu $81,3 \%$, disusul oleh baja $74 \%$, kaca $70 \%$, dan aluminium 64\% (http://www.cepi.org). Dari perspektif lingkungan, penggunaan 1 ton kertas bekas untuk menggantikan pulp mekanis, dapat menghemat kayu sebanyak $2 \mathrm{~m}^{3}$ atau setara dengan hutan seluas $150 \mathrm{~m}^{2}$. Sedangkan untuk menggantikan pulp kimia, 1 ton kertas bekas dapat menghemat kayu sebanyak $4 \mathrm{~m}^{3}$ atau setara dengan hutan seluas $300 \mathrm{~m}^{2}$ (http://www.eko-paket.si). Selain penghematan kayu, keunggulan aspek lingkungan dari penggunaan kertas bekas dibandingkan dengan serat virgin adalah penghematan energi dan penurunan emisi gas serta efluen limbah padat dan cair (http://conservatree.org).

Proses daur-ulang umumnya disadari mampu menghemat sumber daya alam dan energi. Kesadaran semacam inilah yang mendorong laju daur-ulang kertas terus meningkat. Tetapi satu hal sering terabaikan yaitu bahwa biaya daur-ulang harus tetap serendah mungkin (Catlin dan Wang, 2013). Biaya daur-ulang kertas bekas mencakup biaya bahan baku (43\%), listrik (16\%), dan bahan kimia (8\%). Manajemen strategis perlu diterapkan agar komponen biaya pengolahan kertas bekas dapat diturunkan sehingga proses berjalan efektif dan efisien (Yilmaz, 2015). Saat ini kertas bekas sebagai bahan baku industri kertas telah menjadi komoditas penting lintas benua. Indonesia sudah masuk ke 10 besar negara pengimpor dan pengguna kertas bekas (http://faostat3.fao.org/ browse/F/FO/E). Standar kertas bekas, sebagai salah satu instrumen bisnis, telah disusun oleh berbagai negara maju seperti Amerika Utara,
Eropa, serta Jepang. Sejalan dengan peningkatan peran yang disandangnya, terminologi kertas bekas pun mengalami evolusi mulai dari waste paper, secondary fiber, recycled fiber, recovered paper, dan terakhir menjadi paper for recycling sebagaimana dinyatakan dalam standar Eropa EN643 (http://www.cepi.org).

Kertas bekas tidak boleh lagi dianggap sebagai limbah, tetapi kertas bekas adalah sumber daya industri. Oleh karena itu perlu penegasan terkait kriteria kertas bekas sebagai bahan baku industri kertas. Kriteria tersebut bisa mencakup pemenuhan persyaratan bahan baku, spesifikasi, informasi mutu, serta jaminan tidak ada kontaminasi dan kandungan bahan berbahaya (http://ipts.jrc.ec.europa.eu). Sesuai dengan karakter sumber daya, maka peningkatan penggunaan kertas bekas yang terus menerus, tuntutan manajamen proses yang efektif dan efisien, serta upaya penurunan biaya produksi, mendorong timbulnya visi baru dalam industri kertas. Di masa depan industri kertas tidak hanya menghasilkan kertas, tetapi juga harus menghasilkan produk lain baik kimia maupun energi, yang dikenal sebagai pabrik kertas multi produk. Visi ini sejalan dengan adanya kebutuhan penerapan konsep biorefinery di industri kertas (Chambost dkk, 2008). Selain itu karena bahan baku berasal dari produk kertas itu sendiri, maka sistem rantai pasokan terbalik yang mencakup sistem pengumpulan kertas bekas, perlu dicermati dan dioptimalkan agar pasokan bahan baku tidak terganggu (Kara dan Onut, 2010).

Industri kertas yang berbahan baku kertas bekas, menghasilkan berbagai aliran samping berupa rejek dan sludge yang dapat dimanfaatkan kembali untuk keperluan lain. Untuk produksi kertas lainer dan medium yang menggunakan kertas bekas jenis OCC sebagai bahan bakunya, jumlah rejek sekitar 1-6\% sedangkan sludge $0-1 \%$. Pada umumnya rejek dan sludge dibuang sebagai bahan urugan tanah, padahal sebenarnya juga dapat diubah menjadi energi dengan nilai kalor lebih dari $11 \mathrm{GJ} /$ ton untuk rejek dan 4,7 - 8,6 GJ/ton untuk sludge (Gavrilescu, 2008). Sludge berasal dari pengolahan limbah atau fasilitas deinking, sedangkan rejek berasal dari hidropulper, screen, dan cleaner. Rejek biasanya terdiri dari $45 \%$ plastik, $21 \%$ kertas, $10 \%$ logam, 24\% lain-lain (Haynes dkk, 2009). Menurut Setiawan dkk (2014) komposisi rejek sesudah pemisahan logam adalah $49,25 \%$ serat dan $50,75 \%$ plastik, dimana komponen plastiknya 
lebih dari 99\% berjenis HDPE. Selain diproses menjadi bahan bakar, rejek juga bisa menjadi bahan baku alternatif, atau dipilah komponennya untuk pemanfaatan lebih lanjut. Sebagai contoh bila komponen plastik dan serat dalam rejek dipisahkan, maka proses pemanfaatannya juga dapat dilakukan secara terpisah. Plastik dapat dimanfaatkan kembali sebagai bahan plastik daur-ulang maupun bahan bakar, sedangkan serat dapat diubah menjadi bahan baku proses pembuatan kertas. Jadi pada dasarnya tidak ada lagi rejek yang terbuang dari industri kertas tetapi seluruhnya bisa diubah menjadi produk baru yang lain (http://www.cost-e48.net).

Berdasarkan uraian di atas, maka upaya memaksimalkan nilai tambah kertas bekas sangat mungkin dilaksanakan. Upaya ini menjadi amat penting dan kritis pada saat ini dan di masa yang akan datang, karena tumbuhnya industri biomassa yang menggunakan kayu sebagai bahan baku sehingga harga biomassa, termasuk kertas bekas, akan menjadi mahal. Nilai tambah maksimum dari kertas bekas akan sangat berpengaruh pada biaya produksi kertas keseluruhan (http:// reffibre.eu). Pada penelitian ini telah dilakukan upaya meningkatkan nilai tambah kertas bekas dengan mengolah rejek hidropulper daur-ulang kertas bekas dari suatu industri kertas untuk dimanfaatkan komponen seratnya. Selanjutnya dilakukan percobaan pembuatan lembaran kertas skala laboratorium dari komponen serat tersebut. Terhadap lembaran kertas yang dihasilkan dilakukan karakterisasi untuk menentukan jenis kertas apa yang sesuai.

\section{BAHAN DAN METODE}

Pada penelitian ini digunakan rejek hidropulper berasal dari salah satu industri kertas penghasil kertas lainer dan medium dengan kapasitas 120 ton per hari yang menggunakan Old Corrugated Container (OCC) lokal sebagai bahan bakunya. Rejek yang diperoleh dianalisis untuk mengetahui kadar air dan komposisi serta jenis komponen rejeknya mengacu pada pustaka daring Exler,J., 2008, Chemistry of Polymer (http://www.ccmr. cornell.edu). Penanganan rejek dimulai dengan pemisahan komponen logam secara magnetis dilanjutkan dengan pencacahan. Pencacahan dilakukan menggunakan mesin yang mempunyai pisau pencacah dan lubang saringan berukuran sekitar $6 \mathrm{~mm}$. Dari proses pencacahan dihasilkan cacahan rejek dan air dimana air yang terkumpul dipompa dengan debit sekitar $15 \mathrm{~L} /$ menit untuk diresirkulasikan ke mesin pencacah. Cacahan rejek dipisahkan komponen plastik dan seratnya menggunakan saringan kain dan pelat logam berlubang dengan ukuran sekitar $2 \mathrm{~mm}$. Serat disaring kembali menggunakan kain saringan berlubang berukuran sekitar $1 \mathrm{~mm}$. Serat yang tersaring selanjutnya dikeringkan menggunakan panas sinar matahari sampai kandungan airnya kurang dari $10 \%$. Rejek kering ini selanjutnya disiapkan untuk pembuatan lembaran kertas.

Lembaran kertas dibuat dari campuran rejek $(\mathrm{R})$ dan OCC $(\mathrm{O})$ dengan komposisi R:O adalah 100:0, 75:25, 50:50, 25:75, 0:100. R dan $\mathrm{O}$ digiling hingga freeness $300 \mathrm{~mL}$ CSF (Canadian Standard Freeness), kemudian dicampurkan dan dibentuk lembaran kertas dengan gramatur 70,125 , dan $150 \mathrm{~g} / \mathrm{m}^{2}$ tanpa penambahan bahan kimia. Selanjutnya masingmasing kertas disebut 70 GSM, 125 GSM, dan 150 GSM. Klasifikasi dan distribusi panjang serat $\mathrm{R}$ dan $\mathrm{O}$ diamati sebelum pembuatan lembaran menggunakan metode analisis citra $L \& W$ Fiber Tester. Terhadap lembaran kertas kemudian dilakukan pengujian gramatur, ketahanan tarik, ketahanan sobek, ketahanan retak, ketahanan lipat, porositas, kekasaran, Cobb 60, dan kadar air berdasarkan metode uji SNI. Khusus untuk gramatur 125 dan $150 \mathrm{~g} / \mathrm{m}^{2}$ ditambahkan lagi pengujian Ketahanan Tekan Lingkar (RCT) dan Ketahanan Tekan Datar (CMT) sesuai SNI. Hasil pengujian dievaluasi untuk menetapkan jenis kertas yang dapat disarankan dari campuran $\mathrm{R}$ dan $\mathrm{O}$ tersebut, disertai dengan saran untuk meningkatkan mutunya.

\section{HASIL DAN PEMBAHASAN}

\section{Hasil Karakterisasi Rejek Hidropulper}

Kadar air rejek dari hidropulper adalah $1,71 \%$, kondisinya cukup kering, mengandung pengotor logam seperti kawat dan staples. Rejek berukuran sekitar $5-15 \mathrm{~cm}$ dan sesudah pencacahan menjadi $1-5 \mathrm{~cm}$. Setelah proses pencacahan, penyaringan, dan pengeringan diperoleh serat rejek sebanyak 14,92\% dari rejek total hidropulper. Bila proporsi rejek yang terbentuk adalah 1-6\% (Setiawan dkk, 2014), maka dengan kapasitas 120 ton per hari, akan diperoleh serat rejek sebanyak $0,2-1,1$ ton per hari. Serat rejek ini berpotensi untuk digunakan kembali sebagai bahan baku produksi kertas. 


\section{Analisis Distribusi Panjang Serat}

Data distribusi panjang serat sangat penting karena fakta selalu menunjukkan bahwa jika serat panjang dan pendek dicampur pada freeness yang sama, maka freeness hasil campurannya selalu tidak sama. Kejadian ini disebabkan oleh distribusi panjang serat yang berbeda pada tingkat penggilingan yang sama. Oleh karena itu freeness yang secara tradisional digunakan sebagai indikator penggilingan, harus didukung dengan data lain seperti nilai retensi air, morfologi serat, dan klasifikasi serat (Rachmanasari dan Hidayat, 2011). Hasil analisis klasifikasi serat stok rejek dan OCC yang digiling hingga $300 \mathrm{~mL}$ CSF adalah sebagai berikut:

Tabel 1. Distribusi Panjang Serat dan Panjang Serat Rata-Rata

\begin{tabular}{lcc}
\hline $\begin{array}{c}\text { Distribusi Panjang Serat } \\
(\mathrm{mm})\end{array}$ & $\begin{array}{c}\text { Rejek } \\
(\%)\end{array}$ & $\begin{array}{c}\text { OCC } \\
(\%)\end{array}$ \\
\hline $0,2-0,3$ & 16,05 & 8,85 \\
$0,3-0,5$ & 28,80 & 19,05 \\
$0,5-0,9$ & 36,55 & 36,75 \\
$0,9-1,7$ & 13,85 & 21,70 \\
$1,7-7,5$ & 4,75 & 13,65 \\
Panjang Serat & 0,68 & 0,98 \\
Rata-Rata (mm) & & \\
\hline
\end{tabular}

Hasil analisis pada Tabel 1 menunjukkan bahwa kandungan serat panjang OCC lebih banyak dibandingkan dengan rejek, atau sebaliknya. Ini berarti serat rejek sendiri tidak dapat membangun kekuatan lembaran kertas secara maksimal, dan akan memerlukan bantuan. Bantuan tersebut bisa berupa penambahan komponen serat panjang atau bahan kimia penguat. Kondisi ideal mungkin dapat tercapai bila kedua serat ini dicampur karena akan saling menutupi kekurangan masing-masing. Serat rejek akan berkontribusi pada membangun struktur fisik lembaran (formasi), sementara OCC berperan membangun sifat kekuatan lembaran. Dengan panjang serat rata-rata yang cukup berbeda antara serat rejek dan serat OCC, maka komposisi campuran keduanya untuk membentuk lembaran kertas yang diinginkan dapat diprediksi.

\section{Indeks Kekuatan sebagai Parameter Bebas Gramatur}

Kekuatan kertas adalah parameter mutu kertas yang merupakan fungsi gramatur. Pada tulisan ini digunakan parameter indeks tarik, indeks sobek, dan indeks retak masing-masing sebagai representasi dari ketahanan tarik, ketahanan sobek, dan ketahanan retak. Indeks kekuatan kertas didefinisikan sebagai perbandingan nilai kekuatan kertas tersebut terhadap gramaturnya. Dengan demikian dapat dikatakan bahwa nilai indeks kekuatan adalah parameter bebas gramatur dari mutu kertas.

\section{Hubungan Ketahanan Tarik dan Ketahanan Sobek}

Data hubungan sifat ketahanan tarik dan ketahanan sobek sangat penting dalam penilaian keandalan kinerja serat sebagai bahan baku kertas. Kedua sifat ini saling bertolak belakang, sehingga pada saat pengembangan serat memerlukan pengendalian yang ketat karena bila terlalu fokus pada peningkatan ketahanan tarik maka sangat mungkin ketahanan sobeknya turun drastis. Gambar 1 berikut ini menunjukkan hubungan sifat ketahanan tarik dan ketahanan sobek kertas dari stok serat rejek, OCC, dan campuran keduanya. Pada Gambar 1 dapat dilihat relasi kedua sifat kekuatan tersebut pada berbagai gramatur serta komposisi serat rejek dan OCC. Jika dilihat kecenderungannya dari awal hingga akhir, nampak jelas bahwa ada kecenderungan kenaikan nilai ketahanan tarik dan ketahanan sobek secara simultan.

Fakta ini sejalan dengan data distribusi panjang serat (Tabel 1). OCC berfungsi sebagai penguat lembaran kertas. Untuk kertas gramatur 70 GSM ketahanan tarik optimum diperoleh pada komposisi Rejek:OCC sebesar 75:25, sedangkan ketahanan tarik maksimum pada komposisi $100 \%$ OCC. Untuk kertas gramatur 125 GSM ketahanan tarik optimum diperoleh pada komposisi Rejek:OCC sebesar 50:50, sedangkan ketahanan tarik maksimum pada komposisi 100\% OCC. Ini berarti berbagai variasi OCC yang meningkat dari 0 hingga $100 \%$ tidak ada masalah, dapat dipilih pada komposisi manapun tapi direkomendasikan komposisi Rejek:OCC sebesar 50:50 agar 
tujuan pemanfatan kembali serat rejek dapat terpenuhi. Sementara itu untuk gramatur 150 GSM, capaian tertinggi kertahanan tarik terjadi pada komposisi Rejek:OCC sebesar 25:75. Dari hasil ini nampak bahwa semakin tinggi gramatur maka semakin sedikit tambahan OCC yang diperlukan. Perbedaan pola hubungan antara ketiga gramatur ini sangat mungkin terjadi mengingat rejek hidropulper sebagai bahan baku pada pembuatan kertas ini juga keseragamannya kurang baik. Peningkatan keseragaman dapat dilakukan dengan usaha pemilahan yang lebih ketat terhadap kertas bekas yang masuk ke hidropulper (Bobu dkk, 2010).
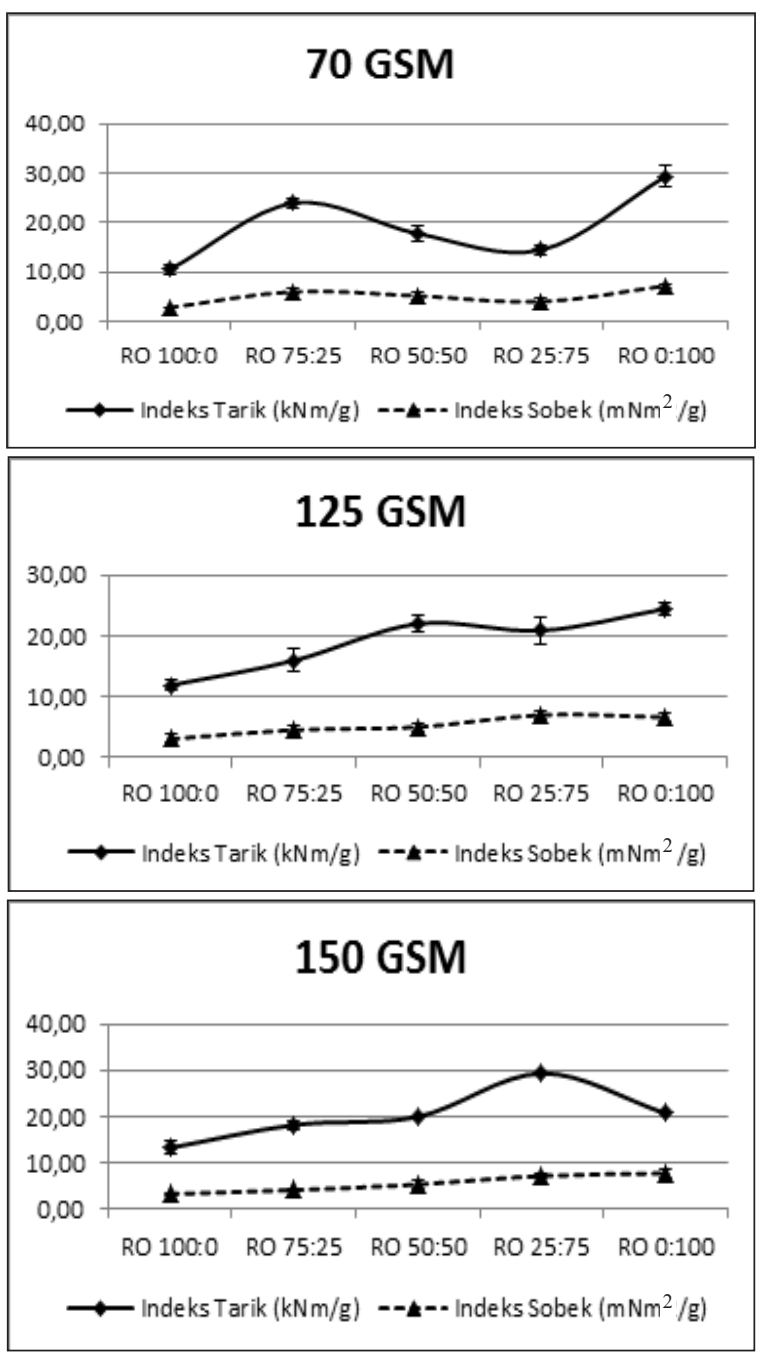

Gambar 1. Hubungan Ketahanan Tarik dan Ketahanan Sobek

\section{Ketahanan Retak}

Parameter kekuatan kertas yang cukup universal, diterima untuk hampir semua jenis kertas, adalah ketahanan retak. Ketahanan retak berguna untuk kertas bungkus, kertas kantong, dan kertas lainer. Karakter indeks retak pada kertas hasil percobaan terlihat pada Gambar 2.

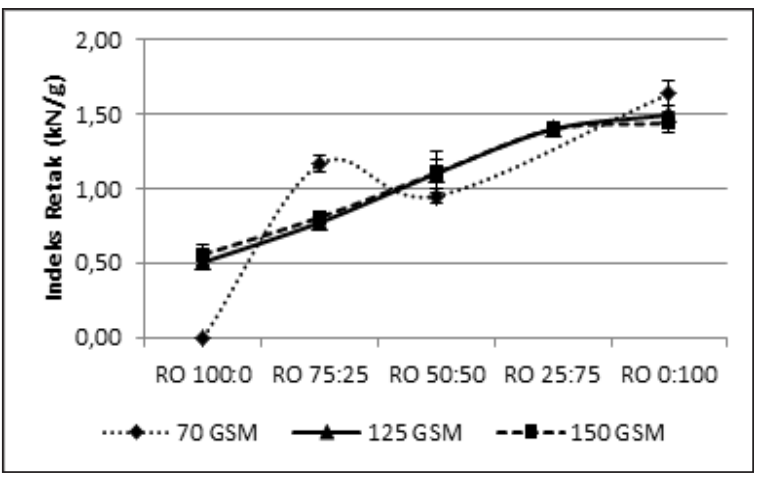

Gambar 2. Pengaruh Komposisi R dan O terhadap Indeks Retak

Pada Gambar 2 dapat dilihat bahwa secara umum indeks retak meningkat dengan naiknya komposisi OCC. Meskipun demikian pada kertas gramatur 70 GSM ada sedikit fluktuasi perubahan, sementara gramatur 125 dan 150 GSM relatif stabil perubahannya. Data indeks tarik, sobek, dan retak menunjukkan bahwa kekuatan lembaran kertas yang terbuat dari rejek hanya bisa dibangun pada gramatur tinggi. Bahkan pada gramatur 70 GSM dengan komponen serat rejek 100\% indeks retak nilainya nol. Untuk keperluan peningkatan mutu kertas ini, cara mekanis (refining) agak sulit diterapkan pada serat rejek, mengingat distribusi seratnya yang dominan pendek. Tetapi cara kimia dan penambahan serat penguat masih memungkinkan untuk meningkatkan kekuatan kertas ini.

\section{Ketahanan Lipat, Daya Regang, dan Tensile} Energy Absorption (TEA)

Meskipun ketahanan lipat jarang dikaitkan dengan kertas kemasan, namun ketiga parameter ini penting bila kertas akan difungsikan sebagai kertas bungkus atau kertas kantong. Kertas bungkus memerlukan daya lipat yang baik, kertas kantong memerlukan daya regang dan TEA yang sesuai. TEA identik dengan tingkat internal bonding dari lembaran, sementara ketahanan lipat bisa menjadi indikator kekuatan daya pakai (durabilitas) kertas. Pada Gambar 3 nampak hasil uji ketahanan lipat untuk ketiga gramatur kertas. Secara umum ketahanan lipat meningkat dengan naiknya komposisi OCC. Tetapi untuk kertas 70 GSM agak berfluktuasi. Fakta ini 
menunjukkan sifat kelenturan serat rejek kurang baik dibandingkan dengan OCC. Serat rejek tidak dapat digunakan untuk kertas yang memerlukan ketahanan lipat tinggi.

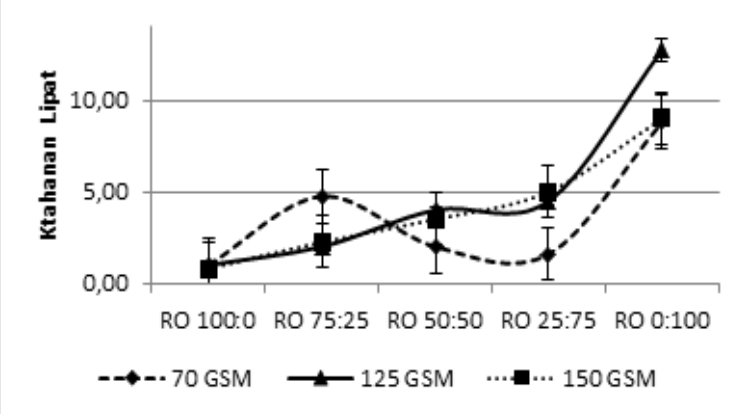

Gambar 3. Pengaruh Komposisi R dan O terhadap Ketahanan Lipat

Gambar 4 menunjukkan bahwa komponen OCC dalam stok berkontribusi pada peningkatan nilai daya regang. Sifat ini diperlukan untuk kertas kemas yang memerlukan ketahanan terhadap beban kejutan, agar kertas tidak langsung putus saat mendapat beban tinggi tetapi ada ruang untuk mengalami peregangan terlebih dulu.

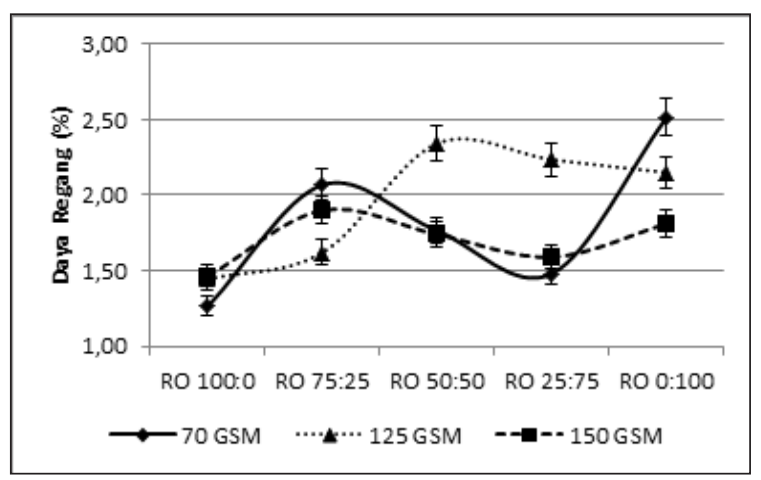

Gambar 4. Pengaruh Komposisi R dan O terhadap Daya Regang

TEA menggambarkan kekuatan ikatan antar serat dalam lembaran. Kertas kantong membutuhkan nilai TEA yang cukup tinggi. Kertas hasil percobaan dengan gramatur 125 GSM memperlihatkan pencapaian nilai TEA yang paling tinggi untuk ketiga jenis kertas yang dibuat, sebagaimana ditunjukkan pada Gambar 5. Sementara kertas 70 GSM, TEA nya paling rendah sehingga tidak sesuai bila digunakan menjadi kertas kantong. Secara umum dapat dilihat bahwa makin tinggi komposisi OCC maka makin besar nilai TEA.

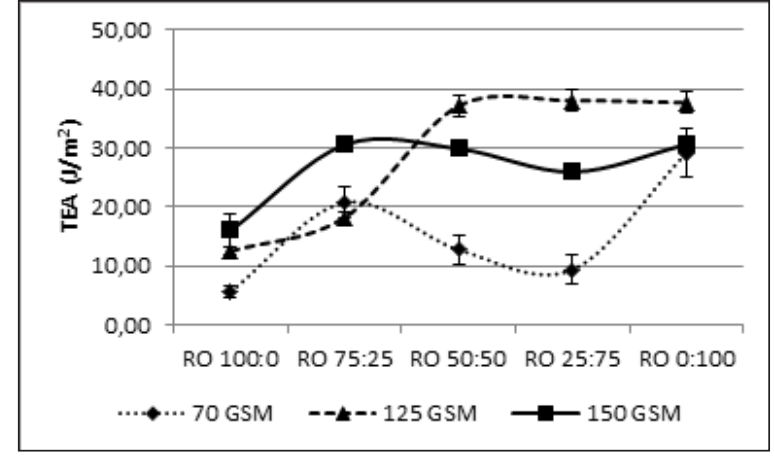

Gambar 5. Pengaruh Komposisi RO terhadap TEA

\section{Daya Serap Air dan Kadar Air}

Daya serap air diuji dengan metode Cobb-60. Parameter ini penting bila kertas akan mengalami kontak dengan cairan misalnya cairan tinta saat proses cetak atau cairan adesif saat pengeleman. Data hasil uji Cobb -60 nampak pada Gambar 6, dimana nilai Cobb-60 seluruh jenis kertas hasil percobaan berada di atas 150 . Ini berarti kertas masih bersifat unsized. Bila target nilai Cobb-60 telah ditetapkan maka tidak terlalu sulit untuk mendapatkannya dengan cara menambahkan bahan kimia seperti alkenyl succinic anhydride (ASA), alkenyl ketene dimer (AKD), atau rosin size.

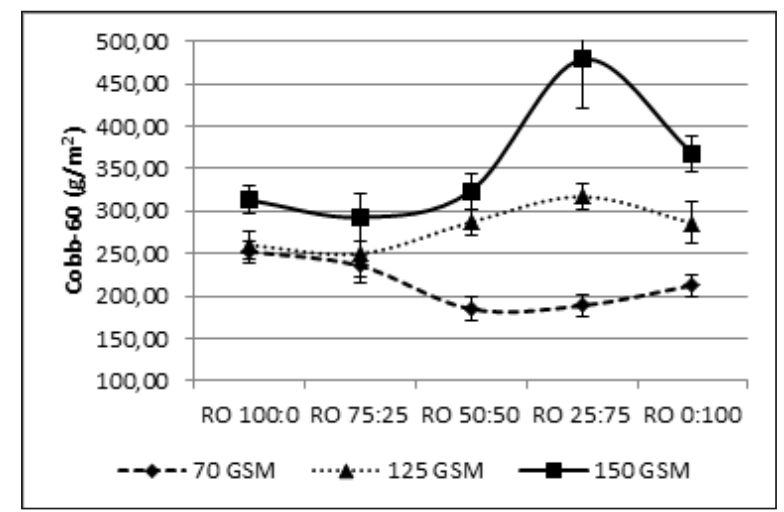

Gambar 6. Pengaruh Komposisi R dan O terhadap Daya Serap Air (Cobb-60)

Sementara itu nilai hasil uji kadar air masih menunjukkan angka yang normal, yaitu $5-7 \%$, sesuai dengan sifat higroskopis kertas yang akan mengalami kesetimbangan terhadap kondisi udara disekitarnya. Data pada Gambar 7 juga memperlihatkan bahwa komponen serat rejek kurang begitu higroskopis dibandingkan dengan 
serat OCC. Kondisi ini kemungkinan disebabkan oleh tingkat "kerusakan" serat rejek lebih tinggi dari serat OCC. Serat rejek adalah sisa dari serat OCC sesudah hidropulper, dan mengalami perlakuan lagi sebelum digunakan sebagai bahan baku pembuatan kertas. Akibatnya komponen higroskopis di permukaan serat rejek menjadi jauh lebih sedikit.

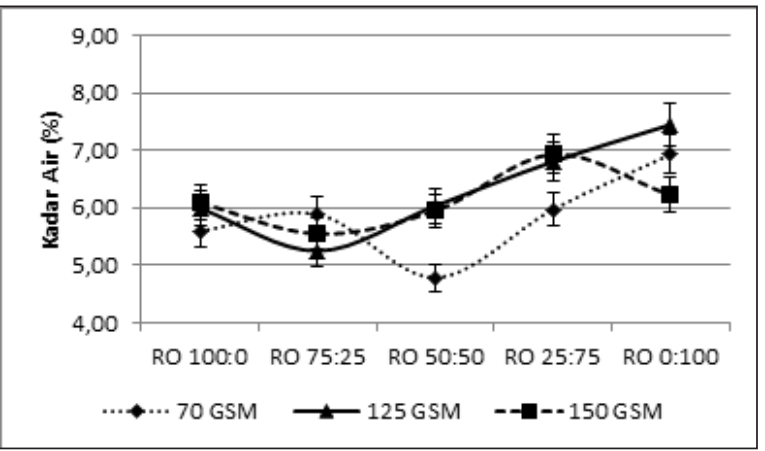

Gambar 7. Pengaruh Komposisi R dan O terhadap Kadar Air

\section{Porositas dan Kekasaran}

Kertas hasil percobaan gramatur 70 GSM memiliki porositas tertinggi dibandingkan dengan kedua jenis kertas lainnya, sebagaimana ditunjukkan pada Gambar 8.

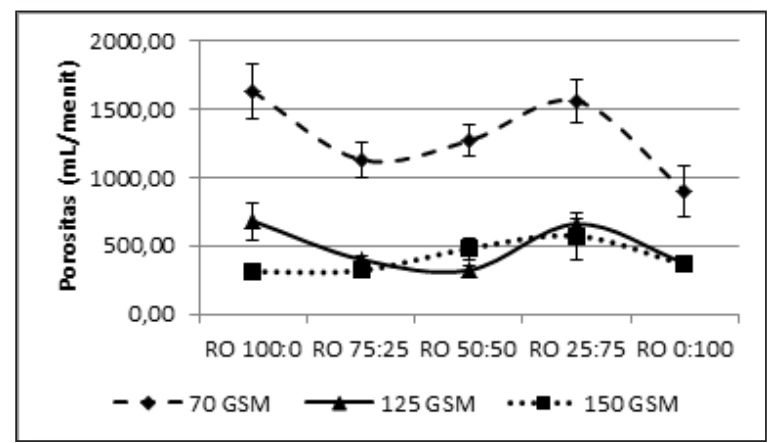

\section{Gambar 8. Pengaruh Komposisi R dan O} terhadap Porositas

Hal ini dapat dipahami karena pada saat pembuatan kertas (handsheet) besarnya beban pengepresan untuk ketiga jenis kertas tersebut sama, padahal jumlah massa per satuan luasnya berbeda. Akibatnya kertas yang gramaturnya lebih tinggi menjadi lebih padat sehingga porositasnya rendah. Meskipun demikian pada untuk gramatur
125 dan 150 GSM, pada mulanya kertas gramatur 150 paling rendah, tetapi kemudian bergeser sedikit hingga kertas gramatur 125 yang paling rendah. Secara numerik nilai porositas ini sebenarnya hanya bergeser sedikit sehingga bisa diangap sama. Uji porositas adalah salah satu uji fisik kertas yang variasinya cukup besar.

Gambar 9 menunjukkan nilai kekasaran permukaan kertas yang kontak dengan wire (wire side). Penambahan jumlah OCC pada stoknya menyebabkan permukaan kertas semakin licin. Hal ini kemungkinan besar terjadi karena OCC masih banyak mengandung bahan kimia dibandingkan dengan rejek. Pada saat lembaran dibentuk bahan kimia ini dapat bertindak seperti "pendarihan permukaan". Sementara pada rejek bahan kimia tersebut sudah tidak ada, karena rejek telah mengalami beberapa perlakuan, khusunya pada saat pemisahan komponen serat.

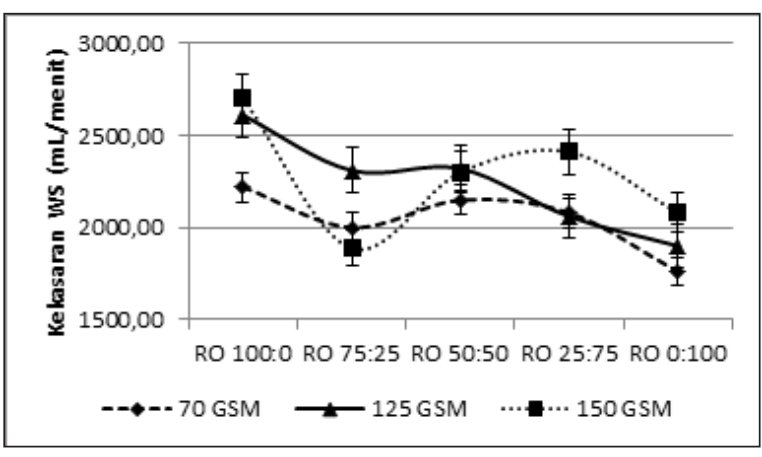

\section{Gambar 9. Pengaruh Komposisi R dan O terhadap Kekasaran}

\section{Ketahanan Tekan Lingkar (RCT) dan Ketahanan Tekan Datar (CMT)}

Meskipun parameter RCT kurang representatif dalam menunjukkan kinerja kertas lainer (Hidayat, 2012), parameter ini tetap digunakan untuk evaluasi mutu kertas lainer. Nilai parameter ini akan mempengaruhi daya tahan tumpuk kotak karton gelombang saat digunakan sebagai kemasan. Gambar 10 menunjukkan bahwa komponen serat rejek memberikan kontribusi penting pada nilai RCT. Kecenderungannya secara umum terlihat RCT turun dengan naiknya komposisi OCC. Nilai RCT dapat ditingkatkan dengan memperbesar komposisi serat rejek. Nilai RCT dapat ditingkatkan lebih lanjut menggunakan bahan kimia. 


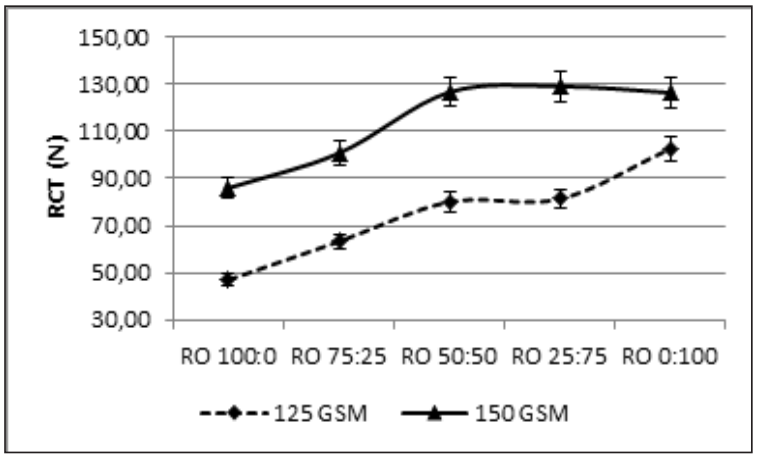

Gambar 10. Pengaruh Komposisi RO terhadap Ketahanan Tekan Lingkar (RCT)

Parameter CMT penting pada kertas medium untuk memberikan nilai efek cushioning saat kotak karton gelombang digunakan sebagai kemasan. Seperti pada RCT, nampaknya komponen serat rejek memberikan kontribusi nyata terhadap nilai CMT, seperti ditunjukkan pada Gambar 11. Dengan meningkatnya komposisi komponen OCC, nilai CMT cenderung sedikit turun. Nilai CMT kertas hasil percobaan gramatur 150 sedikit lebih tinggi dari gramatur 125. Ini gejala normal karena CMT tergantung pada besarnya gramatur. Seperti RCT, nilai CMT dapat ditingkatkan lebih lanjut menggunakan bahan kima.

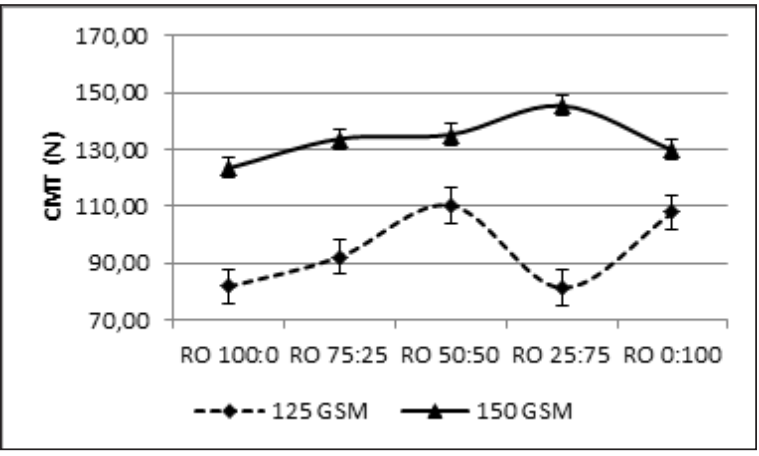

Gambar 11. Pengaruh Komposisi RO terhadap Ketahanan Tekan Datar (CMT)

\section{Usulan Jenis Kertas Berbahan Baku Rejek Hidropulper dan OCC}

Penelitian ini dapat dipandang sebagai studi kasus terbatas dalam rangka penerapan konsep biorefinery di industri kertas, menuju industri kertas yang bersifat multi produk, yaitu bahwa pabrik kertas tidak lagi sekedar menghasilkan kertas tetapi seluruh hasil sampingnya menjadi produk yang bermanfaat (Chambost, 2008; http:// www.cost-e48.net; http://reffibre.eu). Penelitian terdahulu sudah dilakukan bahwa rejek dapat dibuat menjadi bahan bakar (Gavrilescu, 2008; Setiawan dkk, 2014). Pada penelitian ini rejek hidropulper diproses untuk memisahkan komponen plastik dan seratnya. Komponen plastik akan diteliti lebih lanjut menjadi bijih plastik untuk didaur-ulang. Sementara komponen seratnya diproses menjadi kertas daur-ulang pada penelitian ini. Pemanfaatan rejek merupakan upaya memaksimalkan nilai kertas bekas sebagai bahan baku industri kertas (Doshi, 2010; http:// reffibre.eu; Adamopoulos, 2015). Pola ini dapat diterapkan untuk seluruh rejek dan sludge di industri kertas.

Hasil pembahasan penelitian pemanfatan komponen serat dari rejek hidropulper menunjukkan bahwa komponen serat ini sangat layak dibuat kertas kembali dan tidak ada kesulitan apapun saat proses pembuatannya. Namun karena serat rejek ini merupakan "sisa" dari proses proses pengolahan kertas bekas dan mengalami perlakuan lanjutan sebelum digunakan untuk pembuatan kertas, maka terdapat beberapa kekurangan bawaan dari serat rejek. Tetapi kekurangan serat rejek tersebut dapat diatasi menggunakan OCC, hasilnya terlihat bahwa stok atau furnish campuran tersebut berpeluang untuk ditingkatkan mutunya lebih lanjut. Peningkatan mutu furnish campuran dapat dilakukan secara mekanis (penggilingan bila freeness awal masih tinggi, fraksionasi), kimia (penambahan $d r y$ strength, sizing agent), dan serat penguat (dengan serat panjang hasil fraksionasi misalnya).

Lembaran kertas 70 GSM hasil percoban memiliki ketahanan tarik dan ketahanan sobek yang cukup baik, tetapi ketahanan retaknya terlalu rendah bahkan 0 saat furnish terbuat dari $100 \%$ serat rejek. Ketahanan lipat dan daya regangnya cukup baik, tetapi nilai TEA rendah. Kertas gramatur 70 GSM tidak mungkin bisa menjadi kertas kantong karena TEA rendah. Bila nilai ketahanan retak lembaran ditingkatkan, maka kertas gramatur 70 GSM bisa menjadi kertas bungkus atau kertas dasar untuk bungkus berlaminasi plastik. Bila dibandingkan dengan SNI 6519 Kertas Dasar untuk Kertas Bungkus Berlaminasi Plastik, maka karakteristik kertas 70 GSM pada berbagai komposisi RO yang diteliti memiliki kisaran nilai mutu seperti pada data Tabel 2 . 
Tabel 2. Perbandingan dengan Kertas Dasar Bungkus Berlaminasi Plastik (SNI 6519)

\begin{tabular}{lcc}
\hline \multicolumn{1}{c}{ Parameter } & Persyaratan Mutu SNI 6519 & Kisaran Nilai Mutu Kertas 70 GSM \\
\hline Gramatur $\left(\mathrm{g} / \mathrm{m}^{2}\right)$ & 70 & 70 \\
Indeks Tarik AM $(\mathrm{kNm} / \mathrm{g})$ & Min. 0,02 & $10-30$ \\
Kekasaran $(\mathrm{mL} / \mathrm{mnt})$ & Maks. 1700 & $1700-2200$ \\
Cobb-60 $\left(\mathrm{g} / \mathrm{m}^{2}\right)$ & Maks. 120 & $200-250$ \\
Kadar Air & Maks. 8 & $5-7$ \\
\hline
\end{tabular}

Tabel 3. Perbandingan dengan Kertas Kemas (SNI 8053.1)

\begin{tabular}{|c|c|c|c|c|c|c|c|c|c|c|}
\hline \multirow{4}{*}{ Parameter } & \multicolumn{8}{|c|}{ Persyaratan Mutu SNI 8053.1} & \multirow{4}{*}{$\begin{array}{c}\text { Kertas } \\
125 \mathrm{GSM}\end{array}$} & \multirow{4}{*}{$\begin{array}{c}\text { Kertas } \\
150 \text { GSM }\end{array}$} \\
\hline & \multicolumn{4}{|c|}{ Kertas Lainer } & \multicolumn{4}{|c|}{ Kertas Medium } & & \\
\hline & \multicolumn{2}{|c|}{$125 \mathrm{GSM}$} & \multicolumn{2}{|c|}{$150 \mathrm{GSM}$} & \multicolumn{2}{|c|}{$125 \mathrm{GSM}$} & \multicolumn{2}{|c|}{150 GSM } & & \\
\hline & A & $\mathrm{B}$ & A & $\mathrm{B}$ & $\mathrm{A}$ & $\mathrm{B}$ & $\mathrm{A}$ & $\mathrm{B}$ & & \\
\hline Gramatur $\left(\mathrm{g} / \mathrm{m}^{2}\right)$ & \multicolumn{2}{|c|}{125} & \multicolumn{2}{|c|}{150} & \multicolumn{2}{|c|}{125} & \multicolumn{2}{|c|}{150} & 125 & 150 \\
\hline Indeks Retak (kN/g), Min. & 2,5 & 2,0 & 2,5 & 2,0 & & & & & $0,5-1,5$ & $0,6-1,6$ \\
\hline Cobb-120 $\left(\mathrm{g} / \mathrm{m}^{2}\right)$, Maks. & \multicolumn{4}{|c|}{80} & \multicolumn{4}{|c|}{-} & $250-450$ & $200-350$ \\
\hline Kadar Air (\%), Maks. & \multicolumn{4}{|c|}{9} & \multicolumn{4}{|c|}{9} & $5,25-7,50$ & $5,50-7,00$ \\
\hline Kekasaran (mL/mnt), Maks. & \multicolumn{4}{|c|}{1500} & \multicolumn{4}{|c|}{ - } & $1900-2600$ & $2100-2700$ \\
\hline RCT (N), Min. & \multicolumn{4}{|c|}{ - } & 123 & 70 & 147 & 100 & $45-20$ & $15-32$ \\
\hline CMT (N), Min. & \multicolumn{4}{|c|}{ - } & 177 & 100 & 213 & 130 & $5-13$ & $7-25$ \\
\hline
\end{tabular}

Indeks tarik dan kadar air lembaran kertas RO $70 \mathrm{~g} / \mathrm{m}^{2}$ dapat memenuhi persyaratan SNI 6519, sedangkan nilai kekasaran dan Cobb-60 yang tidak memenuhi syarat SNI 6519 masih dapat ditingkatkan kualitasnya. Sementara itu untuk kertas gramatur 125 dan 150 GSM, nilai ketahanan tarik dan sobeknya relatif lebih stabil dan menunjukkan peningkatan dengan naiknya komposisi OCC, dibandingkan kertas 70 GSM. Meskipun begitu, nominal besaran nilai tarik dan sobeknya mirip dan masih memadai. Sementara itu nilai ketahanan retaknya lebih tinggi dari kertas 70 GSM, tetapi secara nominal tetap rendah. Untuk gramatur 125 dan 150 GSM, nilai RCT dan CMT paling tinggi saat komposisi serat rejek $100 \%$. Kedua parameter ini khas untuk kertas lainer dan medium. Kertas hasil percobaan gramatur 125 dan 150 GSM dapat direkomendasikan menjadi kertas lainer dan medium, bila beberapa parameter mutunya diperbaiki. Untuk kertas lainer, maka parameter ketahanan retak dan RCT sangat diutamakan. Tetapi untuk kertas medium, maka nilai RCT dan CMT perlu ditingkatkan. Secara umum, kedua jenis kertas bisa menjadi kertas lainer dan medium setelah ada peningkatan mutu sesuai persyaratan. Proses peningkatan mutu yang diperlukan sama seperti kertas 70 GSM. Karakteristik kertas 125 dan 150 GSM pada berbagai komposisi RO yang diteliti, dibandingkan dengan persyaratan mutu SNI 8053.1 kertas kemas memiliki kisaran nilai mutu seperti ditampilkan pada Tabel 3.

Bila dibandingkan dengan SNI, kedua jenis kertas baik 125 maupun 150, masih memerlukan banyak perbaikan agar dapat menjadi kertas lainer dan medium. Pada penelitian ini sebenarnya digunakan non-chemical stock, artinya furnish hanya merupakan campuran serat. Oleh karena itu peluang perbaikan sangat terbuka seperti penambahan bahan kimia penguat untuk memperbaiki indeks retak, Cobb, RCT, dan CMT. Sementara itu komponen OCC dapat difraksionasi sehingga serat panjang dan pendek bisa dipisah dan bila memiliki freeness awal tinggi dapat dilakukan proses refining secara terpisah. Refining dan komponen serat panjang merupakan factor yang untuk peningkatan kekuatan. 


\section{KESIMPULAN}

Kegiatan penelitian ini merupakan studi kasus terbatas dari penerapan konsep biorefinery di industri kertas. Hasil penelitian menunjukkan bahwa komponen serat dari rejek hidropulper yang dicampur dengan OCC sangat layak untuk dibuat kertas, dan memiliki peluang untuk ditingkatkan mutunya lebih lanjut baik dengan cara kimia maupun cara mekanis. Dengan cara ini, nilai kertas bekas dapat ditingkatkan karena biasanya rejek hidropulper tidak dimanfaatkan. Hasil evaluasi lembaran kertas hasil penelitian merekomendasikan bahwa kertas gramatur 70 GSM dapat diarahkan menjadi kertas bungkus, sementara gramatur 125 dan 150 GSM bisa ditingkatkan menjadi kertas lainer dan medium.

\section{UCAPAN TERIMAKASIH}

Penulis menyampaikan ucapan terimaksih yang sebesar-besarnya kepada BBPK yang telah mendanai penelitian ini melalui Anggaran DIPA 2015. Terimakasih juga disampaikan kepada Bapak/Ibu : Aep Surachman, Cucu, Agus, Endang, Sonny Kurnia, Mungki, dan Nena, yang telah membantu melakukan pengolahan rejek, pembuatan kertas, dan pengujian.

\section{DAFTAR PUSTAKA}

Adamopoulos, S., Birmpilis, D., 2015. Use and Properties of Recovered Paper Raw Materials for The Production of Corrugated Board, Proceedings of the $14^{\text {th }}$ International Conference on Environmental Science and Technology, Rhodes, Greece, 3-5 September

Bobu, E., Iosip, A., Ciolacu, F., 2010. Potential Benefits of Recovered Paper Sorting by Advanced Technology, Cellulose Chemistry \& Technology. Vol. 44, No. 10, 461-471

Catlin, J.R., Wang, Y., 2013. Recycling Gone Bad: When the Option to Recycle Increases Resource Consumption. Journal of Consumer Psychology. Vol. 23, No. 1, 122-127

Chambost, V., Mcnutt, J., Stuart, P.R., 2008. Implementing The Forest Biorefinery at Existing Pulp and Paper Mills. Pulp \& Paper Canada. Vol. 109, No. 7, 1-9

Doshi, M., 2010. Trends in Utilization of Recovered Papers. Progress in Paper Recycling. Vol. 19, No. $1,22-25$

Gavrilescu, D., 2008. Energy from Biomass in Pulp and Paper Mills. Environmental Engineering and Management Journal. Vol.7, No.5, 537-546
Haynes, R.D., Malloch, J., Cuddy, K., Nicodimos, E., 2009. Ask the Recycle Mill Gals. Progress in Paper Recycling. Vol. 18, No. 3, 13-20

Hidayat, T. 2012. Analisis Kinerja Ketahanan Tekan Lingkar Sebagai Parameter Mutu Kertas Lainer dan Medium. Jurnal Selulosa. Vol. 2, No. 1, 1-7

Kara, S.S., Onut, S., 2010. A Stochastic Optimization Approach for Paper Recycling Reverse Logistics Network Design Under Uncertainty. International Journal of Environmental Science and Technology. Vol. 7, No. 4, 717-730

Miranda, R., Bobu, E., Grossmann, H., Stawicki, B., Blanco, A., 2010. Factors Influencing a Higher Use of Recovered Paper in The European Paper Industry. Cellulose Chemistry and Technology. Vol. 44, No. 10, 419-430

Rachmanasari, H., Hidayat, T. 2011. Efektivitas Berbagai Indikator Penggilingan Untuk Memprediksi Kualitas Kertas. Jurnal Selulosa. Vol. 1, No. 2, 72-80

Setiawan, Y., Purwati, S., Surachman, A., Watimnea, R.B.I., Hardiani, H., 2014. Pelet Reject Industri Kertas sebagai Bahan Bakar Boiler. Jurnal Selulosa. Vol. 4, No. 2, 57-64

Yilmaz, M., 2015. Recycling Costs: A Research in The Waste Paper Industry, European Journal of Accounting Auditing and Finance Research. Vol. 3, No. 4, 58-68

http://conservatree.org, Comparing Recycled to Virgin Paper, (diakses tanggal 6 Juli 2015)

http://faostat3.fao.org/browse/F/FO/E, Forestry Production and Trade, (diakses tanggal 16 November 2015)

http://ipts.jrc.ec.europa.eu, End-of-Waste Criteria for Waste Paper: Technical Proposal, (diakses tanggal 5 Agustus 2015)

http://reffibre.eu, Maximum Value from Paper for Recycling Towards A Multi-Product Paper Mill, (diakses tanggal 8 Agustus 2015)

http://www.ccmr.cornell.edu, Chemistry of Polymer, (diakses tanggal 7 Juni 2015)

http://www.cepi.org, Paper Recycling Monitoring Report 2013, (diakses tanggal 20 Oktober 2015)

http://www.cost-e48.net, No More Rejects from Papers and Boards Recycling, (diakses tanggal 15 Juli 2015)

http://www.eko-paket.si. Recycling the Fibers on Tetra Pak Cartons, (diakses tanggal 12 Juli 2015)

http://www.paperforrecycling.eu, Paper Recycling - Monitoring Report 2013, (diakses tanggal 10 Agustus 2015) 